\title{
Ligas Acadêmicas: Motivações e Críticas a Propósito de um Repensar Necessário
}

\section{Student Leagues: Motivations and Criticisms Regarding a Necessary Reconsideration}

Pedro Tadao Hamamoto Filho

\author{
PALAVRAS-CHAVE \\ - Educação Médica. \\ - Currículo. \\ - Extensão Universitária. \\ - Ligas Acadêmicas. \\ - Estudantes de Medicina. \\ - Relações \\ Comunidade-Instituição.
}

\section{KEYWORDS}

- Education, Medical.

- Curriculum.

- Univeristy Extension.

- Student Leagues.

- Students, Medical.

- Community Institutional Relations.
Recebido em: 31/10/2010

Reencaminhado em: 13/04/2011

Aprovado em: 05/05/2011

\section{RESUMO}

Ligas Acadêmicas têm ocupado o cotidiano do estudante de Medicina de forma crescente. As motivações pelas quais os estudantes as procuram estão atreladas à necessidade de vivência clínica, de socialização e de qualificação profissional. Muitas Ligas, porém, têm se distanciado do propósito da extensão universitária, abrindo espaço para o currículo paralelo, o preenchimento de lacunas curriculares, a especialização precoce e o reforço de vícios acadêmicos. Diante disso, é necessário repensar as Ligas Acadêmicas no âmbito de sua relevância social e acadêmica, de seus objetivos e de sua pactuação com a formação médica, com a interdisciplinaridade, com o SUS e com princípios éticos, visando à integração entre ensino, pesquisa e extensão universitária, para sanar demandas populacionais e contribuir com a formação médica.

\section{ABSTRACT}

Student Leagues have gained increasing presence in the everyday lives of student doctors. The reasons why students seek them arise from their needs for clinical experience, socialization and professional qualification. However, several Leagues have shifted away from the principles of higher education extension studies, giving rise to a parallel curriculum, filling curricular gaps, providing premature specialization and reinforcing bad learning habits. It is therefore necessary to reconsider Student Leagues in terms of their social and academic relevance, their objectives and responsibility in relation to medical training, interdisciplinarity, the SUS and ethical principles, with a view to integration between education, research and university extension programs, in order to meet public demands and contribute toward medical training. 


\section{INTRODUÇÃO}

Em todo o Brasil, presencia-se a proliferação de Ligas Acadêmicas entre estudantes de Medicina. Seja em faculdades tradicionais, seja em faculdades com curso recém-iniciado, os estudantes de Medicina buscam criar ou participar de Ligas Acadêmicas. Compreendidas no rol de possibilidades de extensão universitária ou de currículo paralelo, de modo generalizado, as Ligas têm se configurado parte do cotidiano dos estudantes, desde o ingresso no curso médico.

Nas Ligas, os estudantes recebem aulas teóricas, organizam cursos, simpósios e congressos, desenvolvem projetos de pesquisa, participam de atividades de assistência médica em cenários diversos e tomam parte de campanhas e eventos públicos de promoção à saúde. A primeira Liga brasileira foi criada na década de 1920, na Faculdade de Medicina da USP: era a Liga de Combate à Sífilis, criada por estudantes com o intuito de intervir médica e socialmente num problema de saúde pública da época ${ }^{1}$. Durante a ditadura militar, as associações estudantis passaram a questionar o ensino universitário e a aplicabilidade dos conteúdos previstos em seu currículo frente às transformações sociais pelas quais passava o País, abrindo espaço nas escolas médicas para o surgimento de novas Ligas Acadêmicas ${ }^{2}$. A partir da década de 1990, com acentuação no início do século XXI, mais e mais Ligas foram criadas em todo o Brasil, coincidindo com períodos de reformas curriculares e intenso debate político e acadêmico a respeito do perfil do médico a ser formado ${ }^{3,4}$.

Questiona-se se a busca por Ligas Acadêmicas, em particular, e por atividades do currículo paralelo, em geral, seja uma tentativa de complementação de conteúdos em currículos que não transmitam segurança aos estudantes ${ }^{5,6}$ ou seja também, a exemplo de outras atividades de extensão universitária, uma tentativa de integração e socialização com colegas e de resposta a indagações profissionais ${ }^{4,7}$.

Quando entendidas, porém, no contexto de currículo paralelo, com prejuízo e subversão da estrutura curricular formal, as Ligas Acadêmicas passam a ser bastante criticadas, especialmente pelas comissões de graduação. Risco adicional à formação médica pode ser oferecido quando as Ligas reproduzem vícios acadêmicos e se tornam espaço para especialização precoce.

Tanto tem crescido o debate a respeito do impacto das Ligas na formação do médico, que muitos eventos e congressos de educação médica reservam um espaço para essa discussão, que, mesmo discretamente, tem recebido também alguma atenção da literatura mais recentemente. Conquanto não se tenha sistematizado uma revisão bibliográfica a respeito do assunto, dada a escassez de publicações relacionadas, infor- mações da literatura e constatações do cotidiano das Ligas serviram de base para este artigo. Metodologicamente, trata-se de um ensaio em que se discutem criticamente os riscos e benefícios das Ligas na formação médica à luz das motivações dos estudantes que as procuram e das razões pelas quais podem ser criticadas, visando repensar aspectos conceituais das Ligas Acadêmicas.

\section{MOTIVAÇÕES DOS ESTUDANTES PARA PARTICIPAR DE LIGAS ACADÊMICAS}

Estudo conduzido na Faculdade de Medicina da USP de Ribeirão Preto investigou as principais atividades extracurriculares de seus alunos de graduação em Medicina. A atividade mais frequentada em 2002 foram as Ligas Acadêmicas (72,6\%), com significativo aumento em relação a 1999, quando eram frequentadas por $58,5 \%$ dos alunos. Os autores creditam este aumento ao crescimento do número de Ligas na instituição ${ }^{4}$, onde, posteriormente, um estudo investigou as concepções dos estudantes sobre as vivências e papéis das atividades extracurriculares. Novamente, a participação em Ligas foi a mais frequentemente relatada, e a principal motivação para participar delas foi a aproximação da prática médica. A participação em Ligas girou em torno de $70 \%$ a $80 \%$ do primeiro ao quarto ano, com redução expressiva durante o internato, o quinto e o sexto anos ${ }^{7}$. Estes números tornam clara a motivação apontada: aproximação da prática médica, haja vista que o internato deve ser, fundamentalmente, a vivência da prática médica, e os alunos desta fase não necessitam buscar em atividades extracurriculares o que têm em sua prática curricular diária.

Esta necessidade de aproximação com a prática clínica reflete o anseio do estudante por reconhecimento social e firmação da autoestima, mitigando sua necessidade psicossocial de ser reconhecido como adulto profissionalmente capaz. As Ligas são vistas como meio de incorporar o papel de médico8 ${ }^{8}$.

Por outro lado, a procura de estudantes por essa aproximação traz à baila reflexões sobre insuficiências curriculares e descrédito na formação médica ${ }^{7}$. Posta de outra forma, esta questão pode ser vista no âmbito da importância da aquisição de experiência clínica num contexto educacional que distancia formação e mundo de trabalho. A alta procura por estágios extracurriculares demonstraria que as expectativas dos estudantes não são contempladas nos currículos formais ${ }^{5}$, refletindo a crença dos alunos acerca da inadequação do currículo ao mercado de trabalho ${ }^{6}$

O distanciamento da formação em relação ao mundo de trabalho também seria a razão pela qual as corporações médicas aceitam e estimulam a participação em estágios extracurriculares, reconhecendo nesse movimento uma coerência com a 
necessidade de aperfeiçoamento da prática clínica, de construção da própria experiência médica. Ainda, seria a assunção de que falta algo no currículo formal - falta ao estudante "botar a mão na massa" -, pois nas aulas formais o aluno é um mero espectador, mas nas atividades extracurriculares pode se identificar ativamente na atenção ao paciente ${ }^{9}$. Para o estudante, a situação refletiria a admissão implícita das escolas médicas de que seu trabalho está pedagogicamente fora de foco ${ }^{8}$. Metodologias de ensino que estimulem a autonomia do estudante e situem o ensino em contato íntimo com a realidade, como o Aprendizado Baseado em Problemas, poderiam suprir as necessidades dos alunos quanto à aquisição de experiência clínica, reduzindo o afã da busca por atividades extracurriculares ${ }^{9}$, mas faltam estudos que demonstrem objetivamente a hipótese. Num pequeno levantamento, Peres ${ }^{10}$ assinalou que, em algumas escolas médicas de São Paulo, mudanças curriculares não foram acompanhadas da redução do número de Ligas.

Integração com colegas e identificação com um grupo seriam outras motivações para a procura por atividades extracurriculares. Como discutem Peres e Andrade ${ }^{11}$, a importância de participar dessas atividades se dá desde o início do curso, com o assédio de calouros por veteranos para que cedo, em sua fase de maior vulnerabilidade emocional, se engajem em alguma atividade, sem reflexões críticas a respeito da necessidade real de participar. As razões desse envolvimento seriam fatalmente influenciadas pelas pressões por integração social e identificação com um novo grupo, bem como pela necessidade de assumir o papel social de médico. Nesse sentido, as Ligas Acadêmicas seriam as atividades que mais contemplariam a necessidade de assumir a representação social do médico pelos estudantes ${ }^{11}$. Por outro lado, essas atividades, por estimularem o senso de pertencimento a um novo grupo social, contribuem para a adaptação dos alunos, com potencial para combater fatores estressantes do curso e da mudança quando do ingresso no curso ${ }^{4}$.

A qualificação do curriculum vitae também é frequentemente apontada como uma das motivações para a participação em atividades extracurriculares. Estudo realizado na Universidade Federal de Minas Gerais mostrou que o interesse por atividades do chamado "currículo paralelo" é motivado pelo desejo de melhorar o currículo, para cerca de $62 \%$ dos estudantes ${ }^{6}$. A preocupação com o ingresso na residência médica surge neste mesmo contexto: a participação em Ligas Acadêmicas alimenta a esperança do aluno de que terá aumentada sua competitividade nos concursos ${ }^{8}$. Essa preocupação faz valer a percepção de que, de certa forma, as Ligas Acadêmicas podem fomentar o ambiente competitivo da escola médica ${ }^{2}$. Deve-se refletir, no entanto, que é muito pequena a importân- cia atribuída à participação em atividades extracurriculares nos processos de seleção para residência médica. Inadvertidos, os estudantes estariam empreendendo esforços e tempo num investimento pouco rentável, sob um ponto de vista bastante pragmático. Por outro lado, as experiências vivenciadas quando da participação nessas atividades podem contribuir no forjar de profissionais mais maduros, propositivos e socialmente engajados - o que seria uma real contribuição das Ligas Acadêmicas.

A ampliação do objeto da prática médica, implícita ou explicitamente, pode ser mais uma razão para que estudantes procurem Ligas Acadêmicas. Tem-se defendido que esta ampliação é possível quando, por intermédio das Ligas Acadêmicas, o estudante atua junto à comunidade como agente de promoção de saúde e transformação social, e utiliza os conhecimentos científicos em prol da população ${ }^{2,12}$. A ação social e o desempenho da cidadania satisfariam expectativas dos estudantes quanto à concepção idealizada da medicina, que, em muitos casos, motiva a escolha da profissão. O agir socialmente através das Ligas Acadêmicas incentiva estudantes a delas participarem.

Por fim, aprender com entusiasmo pode ser um fator contributivo na busca por Ligas Acadêmicas. Tratando-se de uma atividade da qual o aluno pode escolher participar ou não, torna-se um espaço teoricamente livre das formalidades acadêmicas. Nesse espaço, ele não só poderá canalizar suas ansiedades (experiência médica, integração social, melhora do currículo, ampliação da prática médica), como também aprenderá por iniciativa própria, num exercício de autogestão de seu aprendizado - com prazer, portanto. Ainda que nas Ligas possam imperar formalidades, estas são, na maioria das vezes, pactuadas por e com seus pares, suavizando para o aluno o ambiente hierárquico da relação professor-aluno.

\section{RAZÕES DAS CRÍTICAS ÀS LIGAS ACADÊMICAS}

Disfuncionantes, as Ligas Acadêmicas tornam-se alvo de críticas legítimas, entre elas: são espaços inadequados ao preenchimento de lacunas curriculares; podem subverter a estrutura curricular formal; ocupam o tempo livre dos estudantes; podem reforçar vícios acadêmicos; possibilitam o exercício ilegal da medicina quando da falta de supervisão docente; permitem o aprendizado de conceitos e práticas equivocados; abrem espaço à intervenção da indústria farmacêutica; favorecem a especialização precoce; podem se transformar em meras sociedades científicas, desconsiderando-se sua essência de extensão universitária.

Depositar nas Ligas Acadêmicas a expectativa de que suplementem o ensino deficiente em alguma área cria um 
mecanismo de "tapa-buraco", reprovável no contexto de desenvolvimento curricular ${ }^{13}$. Publicações recentes, no entanto, descrevem as Ligas Acadêmicas como importantes na complementação curricular de determinadas especialidades, sugerindo, inclusive, a criação de mais Ligas com esse propósito ${ }^{14-16}$. Questiona-se se as Ligas devem ser utilizadas para preencher lacunas curriculares. Se os currículos não contemplam áreas relevantes à formação profissional, é legítima a iniciativa de estudantes para complementar sua formação. Entretanto, a escola médica não deve apoiar essa iniciativa sem, por outro lado, corrigir a falha em seu currículo. Assim, o foco deve ser direcionado à necessidade de revisão curricular, não a atividades extracurriculares que beneficiarão apenas um grupo de alunos.

Quanto à possibilidade de que as atividades extracurriculares, em geral, e as Ligas Acadêmicas, em particular, subvertam a estrutura curricular formal, convém registrar o relato de Monteiro et al. ${ }^{14}$, que citam como aspecto negativo da participação em Liga Acadêmica a falta a atividades curriculares ${ }^{14}$, realidade compartilhada por muitas escolas médicas. Evidentemente, é na estrutura curricular formal que se forja a competência profissional ${ }^{9}$, mas, se o aluno considera mais importante uma atividade extracurricular, há que se repensar o desenvolvimento e a aplicação do currículo ou, ao menos, a aula ou estágio de que o aluno se ausenta.

Vieira et al. (2004) ${ }^{4}$ observaram que o envolvimento em atividades extracurriculares, para a maioria dos alunos, superava 8 horas semanais - achado confirmado por Peres $(2006)^{10}$ -, ambos na Faculdade de Medicina de Ribeirão Preto/USP, e por Tavares et al. $(2007)^{6}$, na Universidade Federal de Minas Gerais. Conquanto a maioria dos estudantes alegue falta de tempo para atividades não curriculares em razão da carga horária formal, essa falta de tempo não os impede de participar de atividades extracurriculares. Ocupar o pouco tempo livre torna-se uma constante para muitos estudantes, num movimento em direção ao sacrifício do lazer, para maior dedicação ao trabalho e aos pacientes ${ }^{10}$. Constrói-se entre os estudantes um comportamento paradoxal: embora reconheçam a necessidade de tempo para descanso e lazer, tratam de logo ocupar o tempo livre com outras atividades, às quais atribuem valor significativo a ponto de lhes tolher o descanso ou lazer. Questiona-se: quão preparado está o estudante para tomar decisões relativas ao uso de seu tempo? Que ansiedades e crenças the povoam o imaginário, influenciando suas decisões? No caso das Ligas Acadêmicas, que satisfações o estudante nelas deposita para que comprometa seu tempo?

O reforço de vícios acadêmicos também pode ser observado em muitas Ligas Acadêmicas. Num levantamento so- bre as Ligas de Medicina Intensiva do País, observou-se que todas oferecem aulas teóricas. Das 17 Ligas do inquérito, 11 têm atividades de pesquisa e apenas duas têm atividades de extensão ${ }^{15}$. Num estudo com Ligas de Oftalmologia, das 12 elencadas, $83 \%$ oferecem aulas teóricas, enquanto 58\% têm atividades práticas em ambulatório ou pronto-socorro ${ }^{16}$. A Faculdade de Medicina de Botucatu/Unesp dispõe de um Programa de Avaliação de Ligas Acadêmicas em que estas são avaliadas em quatro dimensões: eixo fundamental (objetivos, modelo de gestão e ideologia), vetor de ensino, vetor de pesquisa e vetor de extensão ${ }^{17}$. A primeira aplicação do programa mostrou que as Ligas dessa instituição têm bom desempenho em atividades de ensino, o que não ocorre nos vetores de pesquisa e extensão ${ }^{18}$.

Em síntese, diferentes Ligas de todo o País realizam atividades de ensino, geralmente constituídas de aulas teóricas, mas não têm bem desenvolvidas atividades de pesquisa e extensão. Considerando-se que uma das motivações dos estudantes ao participarem de Ligas é a insatisfação com o currículo, por que repetem nelas a lógica que permeia estruturas curriculares tão tradicionais como as aulas teóricas? Mais: se frequentemente as universidades são criticadas por não terem a extensão universitária tão bem qualificada e impactante, como as Ligas Acadêmicas - a rigor consideradas atividades de extensão universitária - repetem essa falha acadêmica? Nesse sentido, resgata-se o fato de muitas Ligas reforçarem vícios acadêmicos, adicionando-se a motivação de alguns estudantes que as procuram com vistas à qualificação de seu currículo ou para se destacar perante professores, alimentando o ambiente competitivo da escola médica, como apontado por Torres et al. ${ }^{2}$.

A supervisão docente nas atividades das Ligas Acadêmicas é outro aspecto a debater. Na formação médica, aprender com um exemplo, seguindo um modelo, constitui um dos principais mecanismos do processo ensino-aprendizagem. Embora se observe, sobretudo no internato médico, que o contato dos estudantes com a prática clínica se dá principalmente por intermédio de médicos-residentes e médicos do serviço, deve haver um preceptor docente que oficialmente responda pela disciplina ou estágio. Em atividades extracurriculares, frequentemente, não se garante uma adequada supervisão docente. Disso resultaria o aprendizado de conceitos e técnicas incorretos que facilmente se incorporam às práticas profissionais do estudante. A situação se agravaria com o exercício ilegal da profissão. Como discutem Taquette et al. ${ }^{5}$, em muitos estágios extraoficiais, os estudantes desfrutam de autonomia e liberdade incompatíveis com seu nível de formação. Rego ${ }^{9}$ aponta o fato de que, em muitos desses estágios, a supervisão 
se dá sob a forma de um "estar-disponível" em caso de dúvidas. Por sua seriedade e complexidade, essa questão deve chamar a atenção das escolas e corporações médicas: é imprescindível discutir a inserção de estudantes em atividades extracurriculares, e nas Ligas Acadêmicas em particular, haja vista a relevância que estas têm obtido e o risco a que podem expor os estudantes.

Muito se tem preocupado com o ensino do uso racional de medicamentos e a influência que as indústrias farmacêuticas podem exercer sobre os estudantes de Medicina. As Ligas Acadêmicas podem ser espaço propício a essa influência. Buscando fontes de recursos para realizar eventos ou projetos de extensão e pesquisa, é possível que os dirigentes das Ligas aceitem financiamento da indústria farmacêutica. Não se entrará nessa discussão em profundidade, mas ressalte-se o risco dessa aceitação sem uma reflexão crítica sobre seu significado. A situação é mais preocupante quando o financiamento oferecido é condicionado a exigências claramente mercantis aceitas pelos estudantes à revelia da instituição de ensino ou com sua tutela.

O favorecimento da especialização precoce é também um viés das Ligas Acadêmicas. No relato de experiência de uma Liga de Cirurgia Plástica, os autores observaram que, quando os membros ingressavam na referida Liga, o interesse em atuar futuramente na área de Cirurgia Plástica ocorria em 28,6\% dos estudantes. Após um ano de participação na Liga, essa porcentagem subiu para $78,6 \%{ }^{14}$. É natural que estudantes com interesse em determinada especialidade procurem atividades extracurriculares relacionadas à área. Participar dessas atividades, porém, não deve restringir as perspectivas dos estudantes e estreitar sua visão de possibilidades. Não se pode olvidar o fato de os estudantes estarem se graduando como médicos gerais - o fato de participarem de determinada Liga não os torna mais especialistas no assunto que seus colegas. Com esta premissa, considera-se louvável que algumas Ligas e especialidades médicas reconheçam o risco de especialização precoce e seu ônus na formação médica ${ }^{13}$. Bastos et al. ${ }^{12}$ defendem que "as Ligas não devem ser somente um grupo de estudo sobre determinado tema ou um teste vocacional para uma especialização futura, ou ainda a oportunidade de superespecialização precoce".

Reunidos, os fatores anteriormente discutidos transformam as Ligas Acadêmicas em meras sociedades científicas, que, neste contexto, caracterizam-se como um grupo de alunos de determinado docente, que, por seu turno, ministra aulas (algumas repetidas do currículo formal; ou se inéditas e relevantes à formação, excluem os demais alunos do curso regular). A recompensa dos alunos é ver seu nome publicado em comunicações de congressos ou artigos científicos - quando isso ocorre. Dessa maneira, as Ligas se tornam objeto de satisfação de demandas pessoais de um grupo de alunos ou de um professor. Acrescentem-se à discussão os mecanismos para ingresso nessas Ligas-sociedades científicas. Frequentemente, são baseados em um curso introdutório, seguido de uma prova para ingresso de um número (às vezes arbitrário) de membros. Em alguns casos, há uma análise do curriculum vitae dos candidatos. Eis aqui mais um exemplo de como se reforçam vícios acadêmicos: o parâmetro para a seleção de novos membros segue à risca o modelo mais tradicional dos vestibulares e concursos públicos, escamoteando aspectos democráticos da universidade (por que só um grupo de estudantes pode se "beneficiar" de recursos acadêmicos inalienáveis ao corpo discente?) e aspectos tão defendidos nos modelos de avaliação mais recentes, como competências, habilidades e atitudes. Que justificativas os responsáveis pelas Ligas apresentariam a essa provocação? Seriam elas defensáveis e sustentáveis?

Por fim, se presentes, essas falhas desconstruiriam nas Ligas a essência da extensão universitária. Tem-se constatado que muitas se contentam com a realização de campanhas pontuais de impacto populacional restrito, senão duvidoso. Duvidoso pela característica de feiras de saúde: muitas informações fornecidas ao acaso em curto período, sem acompanhamento longitudinal e que não podem ser ditas educação em saúde, pois não se sabe o quanto contribuem para melhor compreensão da comunidade sobre o processo saúde-doença. Promoção da saúde e prevenção de doenças e agravos devem ser o alvo das Ligas quando de sua atuação junto à comunidade, principalmente com longitudinalidade de ações, até porque programas continuados de extensão devem ter relevância social e ser espaços de construção de conhecimento e de experimentação de formas de cuidado ${ }^{19}$, capacitando estudantes na compreensão do processo saúde-doença, o que, futuramente, poderá qualificar a atenção à saúde.

\section{REPENSANDO AS LIGAS ACADÊMICAS}

Não se pretende desconstruir a importância das Ligas Acadêmicas na formação médica; pelo contrário, defende-se sua relevância. Reconhecer falhas, contudo, é fundamental para corrigir distorções. Isto feito, segue a discussão a propósito de repensar as Ligas Acadêmicas, revendo aspectos conceituais que, bem aplicados, otimizam as Ligas como espaço produtivo não só aos estudantes, mas também à escola médica e à sociedade.

Na proposição de Azevedo e Dini ${ }^{20}$, Ligas Acadêmicas são entidades primordialmente estudantis, que têm à frente um grupo de estudantes dedicados a se aprofundar em determi- 
nado tema e sanar as demandas da população, atendendo aos princípios da universidade de ensino, pesquisa e extensão. Ao considerarem uma ampliação deste conceito, Torres e Olivei$\mathrm{ra}^{2}$ apontam que:

As Ligas devem configurar espaços em que o aluno possa atuar junto à comunidade como agente de promoção à saúde e transformação social, ampliando o objeto da prática médica, reconhecendo as pessoas em seu todo como atores do processo saúde-doença, permitindo ao aluno não só o desenvolvimento científico, mas também o exercício da cidadania.

Para atingirem este perfil, é fundamental que as Ligas promovam uma forte articulação entre ensino, pesquisa e extensão (desta feita, reforçando uma virtude que se espera da universidade). Essa articulação nasce do entendimento de que as atividades relacionadas à capacitação teórica e vivência clínica nas Ligas podem ser úteis na investigação científica e na educação em saúde junto à comunidade; pesquisas podem fomentar discussões teóricas e ter aplicabilidade na abordagem populacional, e esta pode ser campo para pesquisa e oportunidade de aprendizado teórico e prático.

Quanto à dimensão de ensino nas Ligas, estas devem se afastar da lógica conteudista, que prima pela simples transmissão de informações e conhecimento. Há que se experimentar novas formas de aprender e obter informações. As Ligas podem ser espaços úteis para que os professores ousem novas práticas docentes, novas metodologias de ensino, novos cenários para o processo de ensino e aprendizagem. Êxitos obtidos e dificuldades encontradas podem reorientar a prática docente no currículo formal. Os estudantes, por sua vez, gozando da possibilidade de autogestão de seu aprendizado nesse espaço, devem ser incentivados a mudar suas concepções e práticas a respeito do aprender. Se escolhem ocupar seu tempo livre com atividades afins à medicina, que sejam momentos de satisfação. Do ponto de vista de atividades práticas de ensino e aprendizagem, com o acompanhamento de rotinas assistenciais, há que se garantir adequada supervisão docente. Nesse aspecto, cabe ao professor tido como "orientador" da Liga um envolvimento real. A escola médica não deve se omitir da discussão e, frente aos diagnósticos situacionais, deve utilizar mecanismos para correção de falhas.

Sobre as atividades de pesquisa que as Ligas desenvolvem, é necessário refletir por que motivo nem todas apresentam algum tipo de trabalho em congressos e poucas conseguem publicação em periódicos especializados. Na realidade, muito do conhecimento gerado nas atividades das Ligas não se materializa em produtos para divulgação científica, o que deve ser mais explorado. Reconhece-se que há dificuldades, especialmente para graduandos, em conseguir publicações de destaque e também que apresentações de trabalho em congressos têm conotações distintas. Ainda assim, é necessário incentivar os estudantes a que o façam - especialmente se as Ligas forem utilizadas como espaço de iniciação científica, dado o papel complementar da atividade de pesquisa para o graduando ao propiciar melhoria de sua análise crítica, maturidade intelectual, compreensão da ciência e possibilidades futuras, tanto acadêmicas como profissionais ${ }^{21,22}$. A participação de estudantes em programas de iniciação científica é estratégica e deve ser estimulada ${ }^{23,24}$. A curiosidade científica e o ato de investigar podem recriar laços entre ensino, pesquisa e extensão nos domínios universitários, desencadeando processos de intervenção baseados na observação do cotidiano ${ }^{25}$. Se, por outro lado, funcionarem como sociedades científicas em que os estudantes visam apenas incrementar seu currículo e seus laços com docentes, almejando, por exemplo, a publicação de artigos, incorrerão o risco de fraude acadêmica, quando não se observa a diferença entre pertencer a um grupo de pesquisa e contribuir substancialmente com a análise, sistematização e apresentação de dados de pesquisa ${ }^{26}$.

A partir do entendimento das Ligas como uma das possibilidades de extensão universitária entre estudantes de Medicina, enfaticamente defende-se maior inserção das Ligas em projetos junto à comunidade, haja vista a importância da extensão universitária como transformadora da relação entre universidade e sociedade ${ }^{27,28}$. Apesar de parecer óbvia a necessidade de inserção de Ligas Acadêmicas na comunidade, não é o que se tem constatado em alguns estudos ${ }^{15,18}$. As associações estudantis precisam atentar para essas constatações, visando reorientar práticas, de modo que a extensão universitária seja realizada em sua essência e plenitude, nesse caso, pelas Ligas Acadêmicas. Dessa forma, os estudantes poderão ampliar o objeto de sua prática médica como agentes de promoção à saúde e transformação social.

Perpassando esses aspectos de ensino, pesquisa e extensão, as Ligas Acadêmicas têm de ser pensadas num contexto ainda mais amplo. É necessário que sejam relevantes acadêmica e socialmente, que suas atividades tenham impacto no meio onde se desenvolvem, com ganhos para a comunidade científica e a população em geral. Para isso, é preciso que tenham claramente definidos seus objetivos - os estudantes que delas participam têm de conhecer a finalidade maior das Ligas; esses objetivos, por seu turno, devem ser compatíveis com a formação que se espera do médico. Não conseguirão atingir seus objetivos, entretanto, se em suas propostas não houver articulação entre ensino, pesquisa e extensão. 
Transcendendo as práticas educacionais para as ações de trabalho em saúde, as Ligas podem contribuir com a interdisciplinaridade, admitindo alunos de outros cursos de graduação. Em coerência com o que antes se defendeu, é importante que as escolas médicas incluam a interdisciplinaridade em seu currículo, não relegando ao corpo discente iniciativas nesse sentido, conquanto os estudantes possam também, por si mesmos, buscar o trabalho multidisciplinar e multiprofissional, o que certamente contribuirá com seu desenvolvimento profissional e pessoal.

Questões éticas devem ser consideradas quando do funcionamento de uma Liga Acadêmica, notadamente na relação com fontes financiadoras, na execução de projetos de pesquisa e mesmo nas relações entre os membros da Liga. Princípios democráticos também precisam ser valorizados, como, por exemplo, nos critérios para admissão de membros. Finalmente, a articulação com as propostas do Sistema Único de Saúde é fundamental.

Trata-se de um grande desafio aos estudantes implementar em suas práticas nas Ligas Acadêmicas uma abordagem tão ampla, ancorada em tantos princípios e que exija tão estreita concatenação entre atividades de ensino, pesquisa e extensão. Entretanto, a magnitude do desafio não deve desestimulá-los, mas, sim, manter projetada uma imagem-objetivo a ser atingida e que, no desenvolver das atividades, norteará ações e novas propostas. Para isso, é preciso avaliar as Ligas ${ }^{17}$. A importância da avaliação é tão ressaltada nos contextos educacionais e da formação médica, que deve ser abarcada também pelas Ligas Acadêmicas. Avaliá-las propiciará a detecção de distorções a serem corrigidas e êxitos a serem mantidos e socializados com outras Ligas e associações estudantis.

\section{ASPECTOS CONTROVERSOS}

A intervenção institucional das escolas médicas nas rotinas das Ligas Acadêmicas não é ponto consensual. Há escolas que atribuem créditos curriculares aos estudantes quando da participação em Ligas; há escolas que sequer as reconhecem como legítimas. Há quem considere o tema de interesse exclusivamente estudantil, negando-se a discuti-lo, ou pelo desejo de não haver intromissão docente/institucional, ou simples e francamente por desinteresse.

De qualquer forma, as escolas não podem se omitir da discussão, dadas as proporções que as Ligas têm assumido no cotidiano dos estudantes. Nas escolas cujas Ligas são exclusivamente atividades extracurriculares, a relevância da discussão do tema reside no risco do currículo paralelo e da subversão da estrutura curricular formal. Se os estudantes procuram as Ligas para preencher lacunas curriculares, é necessária uma avaliação sistemática dessas lacunas, com vistas ao aperfeiçoamento não apenas do currículo, mas, principalmente, da formação ministrada. No caso das escolas que atribuem créditos às Ligas, parece inaceitável que não se envolvam na discussão: se consideram curriculares essas atividades, precisam de algum tipo de monitoramento da execução das mesmas, seja por intermédio do orientador das Ligas, seja por mecanismos de autocontrole criados pela iniciativa estudantil.

Esse autocontrole é também alvo de controvérsia. Com relação ao mérito, defende-se ser legítimo que estudantes as controlem, tendo em vista o conceito de Liga Acadêmica de Azevedo e Dini ${ }^{20}$ : se são entidades primordialmente estudantis, é de esperar que sejam geridas pelos estudantes. Nesse sentido, destaca-se a contribuição da normatização da abertura e do Programa de Avaliação das Ligas Acadêmicas implementados na Faculdade de Medicina de Botucatu/Unesp, os quais regulamentam ações das Ligas Acadêmicas, sendo ambos iniciativas dos estudantes. A escola, por sua vez, referenda os resultados das avaliações discentes em sua Comissão Permanente de Extensão Universitária ${ }^{3,17}$. Outra contribuição nesse campo se deu com a publicação das Diretrizes Nacionais em Ligas Acadêmicas de Medicina pela Associação Brasileira de Ligas Acadêmicas (Ablam). Adotadas, essas diretrizes poderão formar um conjunto de Ligas com um perfil semelhante, que evite distorções da concepção de Liga Acadêmica, respeitando, naturalmente, as particularidades de cada escola médica. A ausência de uma regulação é propícia não só à proliferação desordenada de Ligas Acadêmicas, como também a que muitas se descaracterizem como extensão universitária.

\section{CONCLUSÕES}

Os estudantes buscam as Ligas Acadêmicas motivados, basicamente, por suas expectativas com relação à profissão e ao curso médico, num movimento de exploração das possibilidades de vivência pessoal, social e profissional. Diante disso, a intensificação da abertura de Ligas Acadêmicas deve suscitar reflexões acerca da estruturação e do desenvolvimento curricular nas escolas médicas e suas relações com o mundo do trabalho.

As distorções conceituais acerca de Ligas Acadêmicas se refletem nas razões pelas quais são frequentemente criticadas. Responsabilizá-las pela complementação curricular pode reconhecer o currículo paralelo e desobrigar a escola médica da necessidade de instaurar mudanças. A importância de avaliar as Ligas Acadêmicas reside na detecção de desvios, como subversão da estrutura curricular, especialização precoce e reforço de vícios acadêmicos.

As proporções que o tema vem ganhando têm se refletido no comportamento dos estudantes e nas consequências 
potenciais à formação médica. Diante disso, impõe-se chamar a atenção das escolas médicas para essa atividade estudantil.

Resgatar nas Ligas Acadêmicas a missão de desenvolver, integradamente, ensino, pesquisa e extensão para o bem da comunidade, com ampliação do objeto da prática médica, é o desafio aos estudantes e associações discentes. Esse resgate deve ser balizado por um repensar das Ligas em termos de sua relevância social e acadêmica, objetivos, pactuação com a formação médica e com o SUS, trabalho interdisciplinar, princípios éticos e compromisso com a essência da extensão universitária. Com essa perspectiva, as Ligas Acadêmicas contribuirão com a formação médica.

\section{REFERÊNCIAS}

1. Burjato Júnior D. História da liga de combate à sífilis e a evolução da sífilis na cidade de São Paulo (1920-1995). São Paulo; 1999. Mestrado [Dissertação] - Faculdade de Medicina. Universidade de São Paulo.

2. Torres AR, Oliveira GM, Yamamoto FM, Lima MCP. Ligas acadêmicas e formação médica: contribuições e desafios. Interface - Comunic. Saúde, Educ. 2008;12(27):713-20.

3. Hamamoto Filho PT, Bôas PJFV, Corrêa FG, Muñoz GOC, Zaba M, Venditti VC et al. Normatização da abertura de ligas acadêmicas: a experiência da Faculdade de Medicina de Botucatu. Rev Bras Educ Med. 2010;34(1):160-7.

4. Vieira EM, Barbieri CLA, Vilela DB, Ianhez Júnior E, Tomé FS, Woida FM et al. O que eles fazem depois da aula? As atividades extracurriculares dos alunos de ciências médicas da FMRP-USP. Medicina (Ribeirão Preto). 2004;37:84-90.

5. Taquette SR, Costa-Macedo LM, Alvarenga FBF. Currículo Paralelo: uma realidade na formação dos estudantes de Medicina da UERJ. Rev Bras Educ Med. 2003;27(3):171-6.

6. Tavares AP, Ferreira RA, França EB, Fonseca Júnior CA, Lopes GC, Dantas NGT et al. O "Currículo Paralelo" dos estudantes de Medicina da Universidade Federal de Minas Gerais. Rev Bras Educ Med. 2007;31(3):254-65.

7. Peres CM, Andrade AS, Garcia SB. Atividades extracurriculares: multiplicidade e diferenciação necessárias ao currículo. Rev Bras Educ Med. 2007;31(3):203-11.

8. Nogueira-Martins MCF, Nogueira-Martins LA, Turato ER. Medical students' perceptions of their learning about the doctor-patient relationship: a qualitative study. Med Edu. 2006;40:322-8.

9. Rego S. Currículo paralelo em medicina, experiência clínica e PBL: uma luz no fim do túnel? Interface - Comunic, Saúde, Educ. 1998;2(3):35-48.

10. Peres CM. Atividades extracurriculares: percepções e vivências durante a formação médica. Ribeirão Preto;
2006. Mestrado [Dissertação] - Faculdade de Medicina de Ribeirão Preto. Universidade de São Paulo.

11. Peres CM, Andrade AS. Atividades extracurriculares: representações e vivências durante a formação médica. Capturado [30 out 2010]. Disponível em: <http://stoa.usp.br/antandras/files/318/1474/Repres_alun_univ_ativ_extracurr.pdf $>$

12. Bastos MG, Andrade CR, Salgado IAS, Paula MT, Brito DJA, Filho NS. Papel das ligas estudantis de apoio à Nefrologia na prevenção da doença renal crônica. J Bras Nefrol. 2007;29(1 supl 1):28-31.

13. Gonçalves RJ, Ferreira EAL, Gonçalves GG, Lima MCP, Ramos-Cerqueira ATA, Kerr-Correa F et al. Quem "liga" para o psiquismo na escola médica? A experiência da Liga de Saúde Mental da FMB - UNESP. Rev Bras Educ Med. 2009;33(2):298-306

14. Monteiro LLF, Cunha MS, Oliveira WL, Bandeira NG, Menezes JV. Ligas acadêmicas: o que há de positivo? Experiência de implantação da Liga Baiana de Cirurgia Plástica. Rev Bras Cir Plást. 2008;23(3):158-161.

15. Neves FBCS, Vieira PS, Cravo EA, Dias M, Bitencourt A, Guimarães HP et al. Inquérito Nacional sobre as Ligas Acadêmicas de Medicina Intensiva. Rev Bras Ter Intensiva. 2008;20(1):43-48.

16. Kara-José AC, Passos LB, Kara-José FC, Kara-José N. Ensino extracurricular em Oftalmologia - grupos de estudo/ligas de alunos de graduação. Rev Bras Educ Méd. 2007;31(2):166-172.

17. Hamamoto Filho PT, Venditti VC, Oliveira CC, Vicentini HC, Ribeiro JTR, Schellini SA. O Programa de avaliação das Ligas Acadêmicas da Faculdade de Medicina de Botucatu/UNESP. Rev Bras Educ Med. 2009;33(4 supl 4):627-628.

18. Hamamoto Filho PT, Venditti VC, Oliveira CC, Vicentini HC, Ribeiro JTR, Schellini SA et al. Avaliação de Ligas Acadêmicas: sociedades científicas ou atividades de extensão universitária? Revista de Medicina. 2010;89:35.

19. Acioli S. A prática educativa como expressão do cuidado em Saúde Pública. Rev Bras Enferm. 2008;61(1):117-121.

20. Azevedo RP, Dini PS. Guia para construção de Ligas Acadêmicas. Assessoria Científica da Direção Executiva Nacional dos Estudantes de Medicina, texto publicado em 10/10/2006, resultado da oficina realizada no EREM da regional Sul II de 2001, em Ribeirão Preto. Disponível em: $<$ http:/ / www.daab.org.br/texto.asp?registro=157>. Capturado 29. out. 2010.

21. Fava-de-Moraes F, Fava M. A Iniciação Científica: muitas vantagens e poucos riscos. São Paulo em Perspectiva 2000;14(1):73-77. 
22. Reinders JJ, Kropmans TJB, Cohen-Schotanus J. Extracurricular research experience of medical students and their scientific output after graduation. Med Educ. 2005;39(2):237

23. Oliveira NA, Alves LA, Luz MR. Iniciação Científica na Graduação: O que Diz o Estudante de Medicina? Rev Bras Educ Méd. 2008;32(3):309-314.

24. Guimarães FM, Cunha JP, Brito JC, Azevedo MA, Suguiyama MP, Silva MT et al. A importância da iniciação científica na formação do profissional médico. Acta Cir Bras. 2001;16 supl 1:6.

25. Maraschin C. Pesquisar e Intervir. Psicol Soc. 2004;16(1); 98-107

26. Rego S. Índice $H$, autoria e integridade na produção científica. Rev Bras Educ Med. 2010;34(2):189-90.

27. Tavares DMS, Simões ALA, Poggetto MTD, Silva SR. Interface ensino, pesquisa, extensão nos cursos de graduação da saúde da Universidade Federal do Triângulo Mineiro. Rev Latino-Am. Enfermagem. 2007;15(6):1080-1085.

28. Guimarães RGM, Ferreira MC, Villaça FM. O debate necessário: a importância da extensão universitária para a formação médica. Cadernos ABEM 2008;4:69-78.

\section{CONFLITO DE INTERESSES}

Declarou não haver.

\section{ENDEREÇO PARA CORRESPONDÊNCIA}

Pedro Tadao Hamamoto Filho

Departamento de Neurologia, Psicologia e Psiquiatria - UNESP.

Distrito de Rubião Jr, s/n ${ }^{\circ}$

Botucatu - São Paulo

CEP 18618-970 - SP

E-mail: pthamamotof@hotmail.com 